\title{
Environmental Sustainability Awareness in the Kingdom of Saudi Arabia*
}

\author{
Uzma KHAN ${ }^{1}$, Mohammad Imdadul HAQUE ${ }^{2}$, Aarif Mohammad KHAN ${ }^{3}$
}

Received: June 28, 2020 Revised: July 12, 2020 Accepted: August 10, 2020

\begin{abstract}
The study attempts to assess the level of environmental sustainability awareness in the Kingdom of Saudi Arabia. In the process, the study tries to assess the impact of extracurricular activities in increasing awareness of environmental sustainability. A survey questionnaire was administered to the students of Prince Sattam University and other universities of Saudi Arabia. The questionnaire comprises statements on simple environmental conservation activities, which we come across on a daily basis. Hypothesis testing is used to identify significant differences across different categories of respondents. Further, the method of binary logistic regression is used to analyze the data. Though all the respondents agree that conserving the environment is important still there are significant differences across categories when it comes to believing in and practicing environmentally-responsible behavior. The results show that environmental awareness can be increased using awareness activities on sustainability issues in a University setting. The study concludes that increasing the number of extracurricular activities on environmental topics as only $38 \%$ of the respondents reported any activity related to the environment in the past year. The findings of this study suggest that increased awareness of environmental issues can boost the sustainability awareness, which will ultimately lead to a sustainable environment.
\end{abstract}

Keywords: Environmental Issues, Awareness, Sustainability, Logistic regression, Saudi Arabia

JEL Classification Code: C01, C12, K32, M14, Q26

\section{Introduction}

The environmental awareness and environmental quality are important indicators to judge how civilized a nation or race is (Jianguo, 2004). The Brundtland Commission Report (1987) suggested that governments have to execute plan to lessen the negative consequences of human activities

*Acknowledgements:

This project was supported by Dean Scientific Research at Prince Sattam Bin Abdulaziz University under the research project number 2020/02/10524.

${ }^{1}$ First Author and Corresponding Author. Assistant Professor, Department of Finance, College of Business Administration, Female Campus, Prince Sattam Bin Abdulaziz University, Saudi Arabia [Postal Address: Alkharj, Riyadh, 11942, Kingdom of Saudi Arabia] Email: u.khan@psau.edu.sa; uzmakhanafridi@gmail.com

${ }^{2}$ Associate Professor, Department of Management, College of Business Administration, Prince Sattam Bin Abdulaziz University, Kingdom of Saudi Arabia. m.haque@psau.edu.sa

${ }^{3}$ Aarif Mohammad KHAN. Self-Researcher. khanaarifeco@gmail.com

(c) Copyright: The Author(s)

This is an Open Access article distributed under the terms of the Creative Commons Attribution Non-Commercial License (https://creativecommons.org/licenses/by-nc/4.0/) which permits unrestricted non-commercial use, distribution, and reproduction in any medium, provided the original work is properly cited. and conserve the environment for upcoming generations. Under commission guidelines, the Kingdom is extremely attentive in applying an additional environmentally-viable action plan in their entire business ventures, both public and private, to respond to the growing worldwide concerns about the environmentally- liveable perception (Albahlal et al., 2017). As one of the emerging nation, the kingdom has elevated environmental concerns due to its accomplishments in natural reserves. The Kingdom is on the edge of a more intolerant attitude towards sustainability disputes although concrete measures still are to be dynamically encompassed or executed by the general public, simultaneously with administration rules and guidelines (Karban 2014).

Environment, alongside being an advantage for lifeassisting process, is also an obligation for any nation state that targets sustainable growth. Environmental features have massive implication for a nation like Saudi Arabia. As a chief crude oil exporting country, oil revenues contribute $70 \%$ of the nation's budget, and it is estimated that a hike in the price of crude oil by $\$ 10$ per barrel will result in an escalation of Gross Domestic Product by 14\% (Hashmi \& Al-Habib, 2013). This is viewed as a key pollutant, globally, with a populaction with a large propensity to consume. However, 
the Kingdom is experiencing the challenges of air pollution, drinking water accessibility, coastal and marine areas vulnerability, controlling of solid and hazardous wastes. These environmental issues are still seen as a lesser concern than other socio-economic disputes like unemployment and poverty. Sustainability advocates adjustment and enhancement that is well-matched with social, ecological, and other boundaries, current, and forthcoming (Gray \& Wiedemann, 1999).

Madsen (1996) describes the concept of awareness as the step toward ecological consciousness that encompasses a subjective pledge to resolve sustainable issues. Schultz (2000) advocated that concern for environmental issues is deeply linked to the notch to which individuals view themselves as part of the natural environment. Sustainability conception and awareness depend on the indulgence of the magnitudes of specific actions, a hunt for awareness, and entire participation with promise to belief (Abolore, 2012). The vital objective of environmental attentiveness should be the elevation of pro-environmental behavior (Duerden \& Wit, 2010). It is foremost essential to know how the citizens of a nation view sustainability and how they react on it, if they are willing to participate in it. Thus, to achieve the principle of sustainability is to bring awareness to those who can make a difference. But what does the common man comprehends about the environment, how does he perceive it, and what efforts, pains and action is he willing to take to save the environment to safeguard sustainable growth? This consciousness about the environment is the initial phase toward organizing individuals to resolve environmental issues. Elementary responsiveness amongst the general public concerning environmental matters relates a lot in accepting the significance of the environment. This alertness would an bring incredible revolution in human approach and etiquette toward Mother Nature and make this planet earth a better place to survive.

Indulgence on the harmful effects of different environmental issues is essential for policymakers in such a way they can react to the possible fears of environmental issues in an efficient manner by understanding inclusive explanations. Individuals and society should recognize diverse environmental problems like air and water pollution, solid waste management, dust deposi, noise, etc., and their associated consequence on the ecosystem (Ziadat, 2010). The present study aims to estimate the environmental sustainability awareness in the Kingdom of Saudi Arabia and put forward measures to improve upon and make this planet a better place to live.

\section{Literature Review}

Issues on the environment have been analysed by scholars and researchers, some of them have mainly focusing on the environmental awareness of university students (Wolfe, 2001; Holt, 2003; Moody et al., 2005; Kilbourne \& Polonsky, 2005; Chuanhuia \& Hanweib, 2011; Zsoka et al., 2012; Awan \& Abbassi, 2013). According to Ziadat (2010), it is the education that can play a major part in educating on environmental awareness and its associated issues. They found that the graduate and postgraduate students at the university are well responsive towards the environmental issues and revealed more inclinations towards caring for the natural resources of the earth. Also, they found that environmental responsiveness does no relate to gender, the young male and female's responsiveness is highly linked with environmental awareness and performance in line with older age people. More or less similar findings were found by Kellstedt et al., (2008) by suggesting that the younger generation is more responsive toward environmental issues than the older generation.

Bradley et al. (1999) found that there was absolutely no dissimilarity among gender in the context of environmental consciousness, however, the approach toward environmental issues differs considerably among gender. Gonzalez and Amerigo (2000) identified that the male students who took business studies as their subject were least concerned towards the environment as compared to their female counterpart. Schusler and Krasny (2010) found that environmental consciousness is interrelated with the environmental approach. University students showed more responsiveness towards environmental matters as compared to adults.

Awan and Abbassi (2013) examined the link between demographics aspect such as sex, earnings, and employment with environmental responsiveness, acquaintance, and performance. They found that the students with high earnings are more environmentally-educated than those whose earnings are less. Thus, the parents' profession has a noteworthy effect on the overall environmental responsiveness. Ogunbonde and Arnold (2012) examined the distribution of environmental consciousness and approaches on socio-demographic categories and found that older respondents were more concerned as compared to the younger regarding environmental issues. In particular male participants are more empathetic than their female's counterpart, but gender did not influence other facets of environmental approaches. Though, occupation and education both had noticeable impact on environmental facts and outlooks. Ziadat (2010) found that environmental awareness is high among females as compared to males. Blocker and Douglas (1997) suggested that no substantial variance exists between gender in pro-environmental behavior and concern.

Tikka et al. (2000) suggested that female students are inclined to show more concern toward the environment than male students, and particularly, the students in biology showed the utmost optimistic attitudes and the maximum 
passions, as they are acquainted with the flora and fauna. On the other hand, there was some proof that students studying technology and economics embraced a negative approach regarding the environment and hardly displayed naturerelated interests compared to others students. They were also of the view that attitudes, the flora and fauna-related activities and understanding about the environment or nature-related matters are correlated with one another. While educational background appeared to affect attitudes, activity levels, and knowledge, there are numerous other fundamental elements.

Dagher et al. (2015) conducted a study on socialization theory, which advocates that individual behavior is designed by gender expectations concerning the cultural context. They identified that the regulating result of gender was found to be important and impact both environmental worries and attitude to green purchasing behavior. Their outcomes discovered that green marketers can benefit by growing levels of environmental anxiety and attitude of both gender. They recognized that educators, marketers, and policymakers must understand the distinctiveness of each market to endorse green behavior. Corcoran and Wals (2004) view that the universities progressively recognize that they have remarkable conservation sense, not only in relation to the energy they consume and the waste they produce, but primarily because they prepared their graduates to deal with apprehensions of sustainability in both their professional and personal lives.

Derckx (2015) explores the elements of attitude and biospheric values, which are the key factors to judge the intent to act pro-environmentally and the definite types of pro-environmental benefits (PEB). These two factors had persistent and considerable outcomes with the dependent variables. Moreover, the socio-demographic elements age and paid work (or not) also often showed noteworthy results. Lastly, the results showed that responsibility, defeatism and perceived costs and benefits enlighten a substantial amount of an individual's attitude concerning PEB. Likewise, habit showed average results.

Leuw et al. (2015), in their study based on the theory of planned behavior (TPB), tried to identify the opinions that encourage young people to move toward proenvironmental behaviors because the younger generation will bear the burden of past and current laxism toward the environment. They are calling for effective tools for behavior change. Saifullah et al. (2017) suggested that the government should promote the environmental awareness program by conducting various activities like workshops, seminar, campaigns and pamphlets particularly targeted to the younger generation. Nguyen (2020) evaluated five parameters that are responsible for evaluate environmental accounting implementation in the mining sector. He found that one of the parameters, stakeholders, had a negligible impact, while the remaining four parameters (coercive pressure of government agencies, environmental awareness of senior executives, business characteristics, qualifications of environmental accounting) have significant effect on environmental accounting implementation in the mining sector.

Lee and Lim (2020) found that environmental concerns had a positive impact on such practices, and the image of internal GSCM practices was established to have an expressively optimistic effect on consumer purchasing behavior. They found a positive image of internal environmental management and eco-friendly design, which are key elements of the internal green supply chain management (GSCM) practices, strengthening the company's eco-friendly image, and ultimately affecting consumer purchasing behavior. They suggested that it is important for companies to evaluate their environmental attitude and make eco-friendly products from a consumer's perspective, differentiating the company strategy by building an eco-friendly corporate image.

\section{Research Methodology}

Based on the previous studies, behaviors/habits are identified, which are related to environmental conservation (Derckx, 2015; Leeuw et al., 2015). Nine statements are provided and respondents are to give their responses as Yes or No. To assess the impact of awareness, two statements are included first asking whether the respondent has studied any course on environment and second, whether there was any activity related to environmental conservation in his university. Also, the survey asks for demographic information on nationality, gender, university, and major. An online survey is sent to the students of various universities in Saudi Arabia. The choice of universities was convenience-based. The researchers received 365 completed questionnaires. This study proposes to test a set of hypotheses related to habits and respondents' categories using students t-test. These hypotheses test for significant differences in environmentally-responsible behaviors in terms of nationality, gender, university, major, and activity in college.

Further, the study uses binary logistic regression to understand the relation between the education-related items and environmental conservation habits. Survey responses coded 1 for 'yes' and 0 for 'no'. The results are estimated through the Maximum Likelihood procedure. Binary logistic regression is the non-linear conversion of simple regression in which the probabilities of the coefficients are controlled to be within 0 and 1 . It is used when the data has two categorical responses. Here, Exp. (b) is the odds ratio which, if greater than 1, denotes that the likelihood of the effect will increase 
with an increase in the causal variables. The opposite is the implication if the odds ratio is less than 1 . The equation to be estimated is as follows:

$$
\begin{aligned}
\ln \left\{\frac{p}{(1-o p)}\right\}= & \alpha+\beta_{1}(V 1)+\beta_{2}(V 2)+\beta_{3}(V 3)+\beta_{4}(V 4) \\
& +\beta_{5}(V 5)+\beta_{6}(V 6)+\beta_{7}(V 7)+\beta_{8}(V 8)
\end{aligned}
$$

Where $\ln \left\{\frac{p}{(1-o p)}\right\}$ is the logs odd ratio; $\alpha$ is the constant term; $V_{s}$ are the variables under study, and $\beta_{s}$ are the coefficients associated with respective variables.

\section{Results}

The results of the survey were analyzed with quantitative data analyzing techniques. The survey was conducted in the unbiased approach, while everyone was free to participate. Total $n=365$ participants actively answered the survey while their data is analyzed to extract the results of the research. The graphical demographic data is defined as follow:

Figure 1 shows that the majority of the participants were Saudi nationals, 52\% were male. As regards majors, 76 studied Business Administration and 79\% were from Prince Sattam Bin Abdulaziz University.

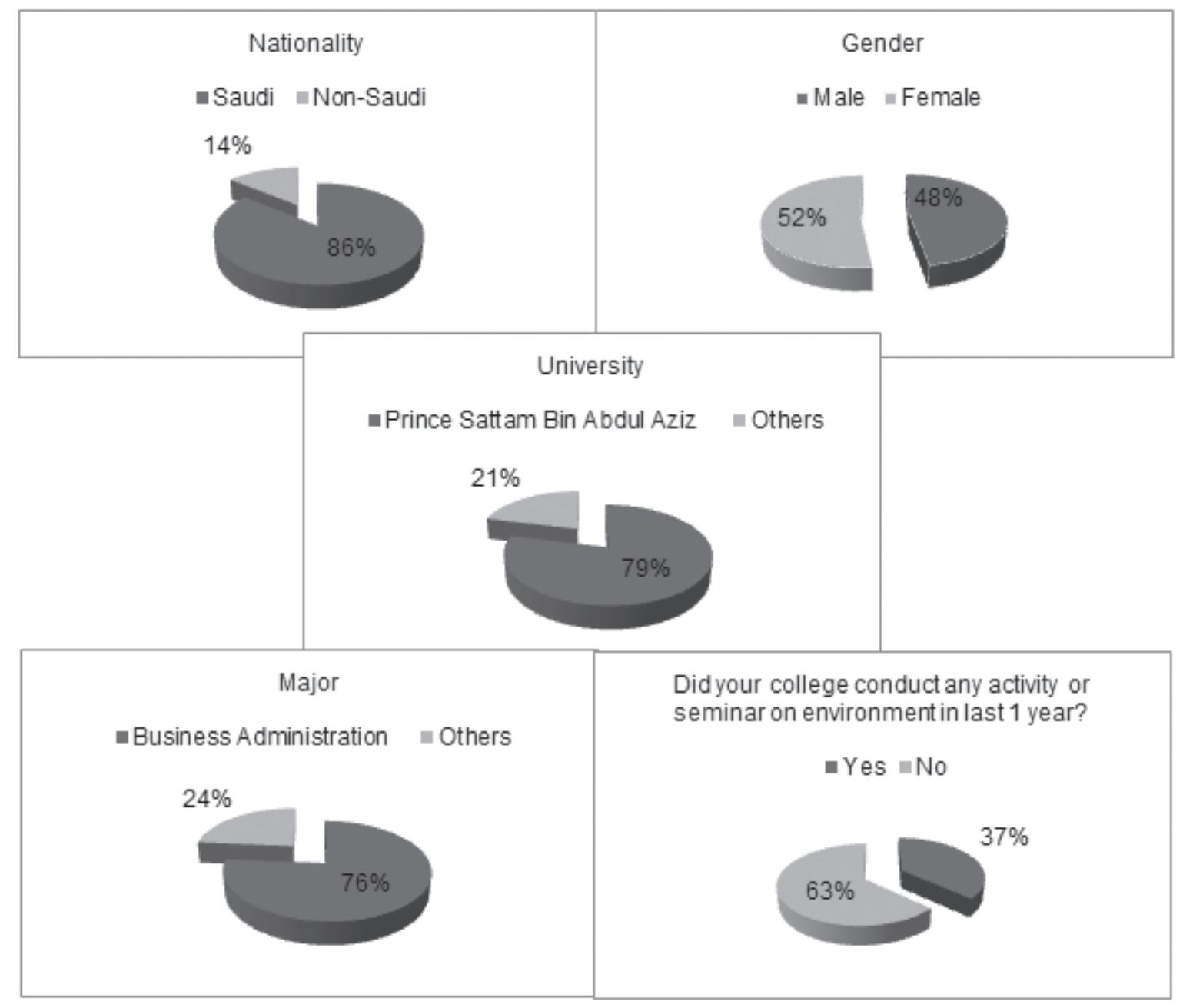

Figure 1: Graphical representation of the respondent categories, i.e., Nationality, Gender, University, Major and Activity 
The majority of the respondents, i.e., $98 \%$ are nature lovers, and all the respondents are aware of the term environmental sustainability and were of the view that environmental resources should be protected and maintained for future generations (see Figure 2).

All respondents agreed that conservation of the environment is important; $88 \%$ close the water tap while brushing their teeth, 91\% switch off the lights when they go out, $33 \%$ print on both sides of the sheet when printing, $48 \%$ uses pro-environmental brands, $54 \%$ take short showers, $38 \%$ keep their engine running while waiting, and 98\% prefers not to waste food (see Figure 3).

The results of hypothesis testing are shown in Table 1 and the mean values of the items are shown in Table 2 .

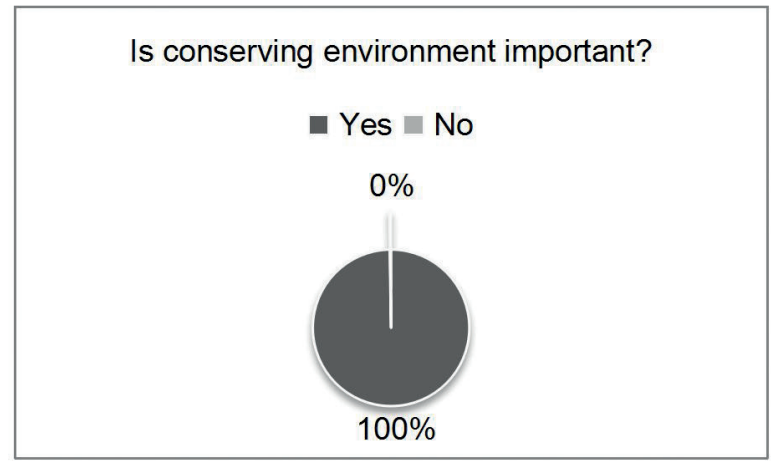

Figure 2: Graphical representation of Environmental Sustainability Awareness
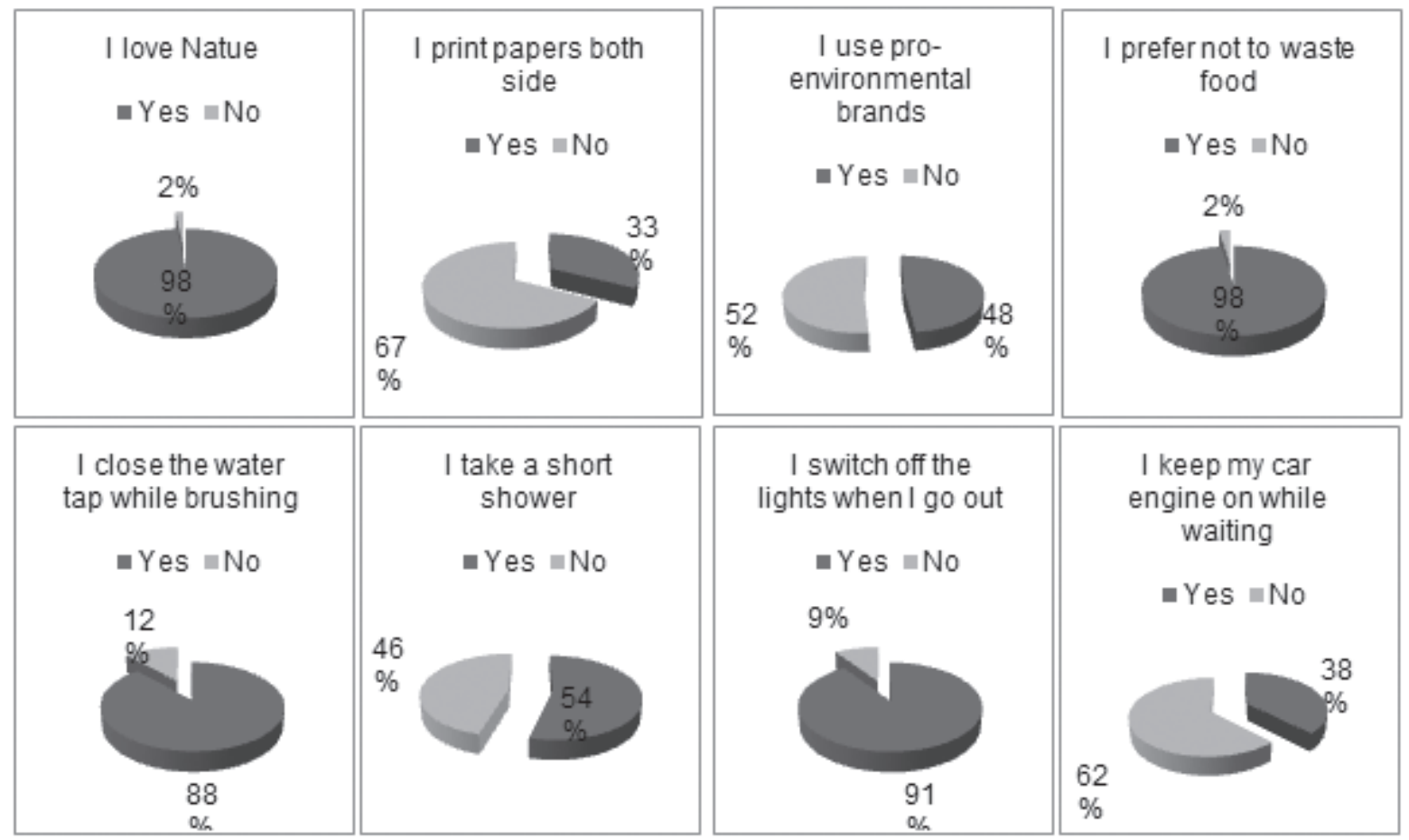

Figure 3: Graphical representation of respondent responses on environmental sustainability awareness questions 
Table 1: Results of hypothesis testing (t-statistics values)

\begin{tabular}{|c|l|c|c|c|c|c|}
\hline & & Nationality & Gender & University & Major & Activity \\
\hline V1 & I close the water tap while brushing & 0.41 & -0.335 & 0.746 & -0.426 & 0.537 \\
\hline V2 & I switch off the lights when I go out & 0.908 & $2.463^{*}$ & -1.247 & 1.277 & -1.676 \\
\hline V3 & I print papers both sides & $2.059^{*}$ & -0.060 & 1.891 & $3.733^{*}$ & $-3.357^{*}$ \\
\hline V4 & I use pro-environmental brands & 0.986 & -1.388 & $2.494^{*}$ & 1.804 & $-3.077^{*}$ \\
\hline V5 & I take a short shower & -1.11 & 1.133 & 0.573 & 1.573 & $-2.703^{*}$ \\
\hline V6 & I prefer not to waste food & 1.223 & 1.154 & 1.572 & 1.688 & -0.212 \\
\hline V7 & I keep my car engine on while waiting & -0.709 & $-2.880^{*}$ & 1.027 & -0.638 & -0.522 \\
\hline V8 & I love nature & -0.191 & 0.938 & 0.267 & 0.4 & -0.173 \\
\hline
\end{tabular}

Table 2: Mean values

\begin{tabular}{|c|c|c|c|c|c|c|c|c|c|c|}
\hline & $\mathbf{N}$ & Mean & G & Mean & $\mathbf{U}$ & Mean & $\mathbf{M}$ & Mean & A & Mean \\
\hline \multirow[t]{2}{*}{ V1 } & 1 & 1.1178 & 1 & 1.1092 & 1 & 1.1215 & 1 & 1.1111 & 1 & 1.1269 \\
\hline & 2 & 1.098 & 2 & 1.1204 & 2 & 1.0909 & 2 & 1.1279 & 2 & 1.1082 \\
\hline \multirow[t]{2}{*}{ V2 } & 1 & 1.0987 & 1 & 1.1322 & 1 & 1.0833 & 1 & 1.1039 & 1 & 1.0597 \\
\hline & 2 & 1.0588 & 2 & 1.0576 & 2 & 1.1299 & 2 & 1.0581 & 2 & 1.1126 \\
\hline \multirow[t]{2}{*}{ V3 } & 1 & 1.6943 & 1 & 1.6724 & 1 & 1.6979 & 1 & 1.724 & 1 & 1.5672 \\
\hline & 2 & 1.549 & 2 & 1.6754 & 2 & 1.5844 & 2 & 1.5116 & 2 & 1.7359 \\
\hline \multirow[t]{2}{*}{ V4 } & 1 & 1.5255 & 1 & 1.477 & 1 & 1.5486 & 1 & 1.5412 & 1 & 1.4104 \\
\hline & 2 & 1.451 & 2 & 1.5497 & 2 & 1.3896 & 2 & 1.4302 & 2 & 1.5758 \\
\hline \multirow[t]{2}{*}{ V5 } & 1 & 1.4459 & 1 & 1.4885 & 1 & 1.4653 & 1 & 1.4803 & 1 & 1.3657 \\
\hline & 2 & 1.5294 & 2 & 1.4293 & 2 & 1.4286 & 2 & 1.3837 & 2 & 1.5108 \\
\hline \multirow[t]{2}{*}{ V6 } & 1 & 1.0287 & 1 & 1.0345 & 1 & 1.0312 & 1 & 1.0323 & 1 & 1.0224 \\
\hline & 2 & 1 & 2 & 1.0157 & 2 & 1 & 2 & 1 & 2 & 1.026 \\
\hline \multirow[t]{2}{*}{ V7 } & 1 & 1.6146 & 1 & 1.546 & 1 & 1.6354 & 1 & 1.6129 & 1 & 1.6045 \\
\hline & 2 & 1.6667 & 2 & 1.6911 & 2 & 1.5714 & 2 & 1.6512 & 2 & 1.632 \\
\hline \multirow[t]{5}{*}{ V8 } & 1 & 1.0159 & 1 & 1.023 & 1 & 1.0174 & 1 & 1.0179 & 1 & 1.0149 \\
\hline & 2 & 1.0196 & 2 & 1.0105 & 2 & 1.013 & 2 & 1.0116 & 2 & 1.0173 \\
\hline & \multicolumn{2}{|c|}{$\mathrm{N}$ : Nationality } & \multicolumn{2}{|c|}{ G: Gender } & \multicolumn{2}{|c|}{ U: University } & \multicolumn{2}{|c|}{ M: Major } & \multicolumn{2}{|c|}{ A: Activity } \\
\hline & \multicolumn{2}{|c|}{ 1:Saudi- 314} & \multicolumn{2}{|c|}{ 1: Male-174 } & \multicolumn{2}{|c|}{ 1:PSAU-288 } & \multicolumn{2}{|c|}{ 1:Business- 279} & \multicolumn{2}{|c|}{ 1:Activity-134 } \\
\hline & \multicolumn{2}{|c|}{ 2:Non-Saudi- 51} & \multicolumn{2}{|c|}{ 2:Female-191 } & \multicolumn{2}{|c|}{ 2.Others- 77} & \multicolumn{2}{|c|}{ 2:Others- 86} & \multicolumn{2}{|c|}{ 2:No activity- 231} \\
\hline
\end{tabular}


Concerning nationality, there is a significant difference only in $\mathrm{V} 3$, which is related to the habit of printing papers both sides as the associated t-statistics of 2.059 is significant (Table 1). Using the paper both sides save paper and conserves the environment. Saudi nationals tend to print both sides more than the expatriates as the mean value of Saudis is 1.6943 , while the mean value of non-Saudis is 1.5490 (Table 2). For all other items, there is no significant difference between Saudi nationals and expatriates. Concerning gender, there is a significant difference in V2 and V7 as the associated significant t-statistics are 2.463 and -2.880 , respectively (Table 1). Males tend to switch off the lights more than the females when they go out as the mean value of males is 1.13, while the mean value of females is 1.05 . Also, females tend to keep their car engines running while waiting more than males as the mean values of females (1.6911) is more than the mean value of males (1.5460) (Table 2).

In terms of difference across universities, there is a significant difference only in $\mathrm{V} 4$, which is related to using pro-environmental brands as the associated t-statistic of 2.494 is significant (Table 1). Students of PSAU tend to use environmental brands more than other university students as the mean value of PSAU students is 1.5486, while the mean value of other university students is 1.3896 (Table 2). Concerning the major selected, there is a significant difference in V3 only as the t-statistic 3.733 is significant (Table 1). Students of business majors tend to use environmental brands more than other university students as the mean value of PSAU students is 1.724 , while the mean value of other university students is 1.5116 (Table 2).
The last hypothesis is associated with the college conducting any activity or seminar on the environment in the last year. Here, three items - V3, V4, and V5 - are significant. There is a significant difference among respondents from those colleges where there was activity in the past year in terms of printing papers on both sides as the associated t-statistics is -3.357 . The mean for the category where there is activity is 1.7359 , while the mean for the category where there is no activity is lower at 1.5672 . Second, there is a significant difference among respondents from those colleges where there was activity in the past year in terms of using proenvironmental brands as the associated t-statistics is -3.077 . The mean for the category where there is activity is 1.5758 , while the mean for the category where there is no activity is lower at 1.4104. Lastly, there is a significant difference among respondents from those colleges where there was activity in the past year in terms of taking a short shower as the associated $\mathrm{t}$-statistics is -2.703 . The mean for the category where there is activity is 1.5108 , while the mean for the category where there is no activity is lower at 1.3657 (Table 1 and 2).

Next, a binary logistic regression is performed to see the effect of any activity on environmental awareness on activities related to environmental conservation. The overall model is significant as the chi-square value 23.026 has a p-value of 0.003 , which is less than 0.05 . Also, the model correctly classifies $64.7 \%$ of the total (Table 3 ). The associate p-value of the Wald's test indicates that, of the twelve items, only item 3 is significant as the associated $\mathrm{p}$-values are lower than 0.095 . These three items are 'I print paper both sides', 'I use pro-environmental brands', and 'I take a short shower'.

Table 3: Results of Binary Logistic regression

\begin{tabular}{|l|c|c|c|c|c|c|}
\hline & B & S.E. & Wald & df & Sig. & Exp(B) \\
\hline I close the water tap while brushing & -0.383 & 0.361 & 1.126 & 1 & 0.289 & 0.682 \\
\hline I switch off the lights when I go out & 0.437 & 0.436 & 1.004 & 1 & 0.316 & 1.548 \\
\hline I print papers both sides & 0.555 & 0.242 & 5.272 & 1 & 0.022 & 1.742 \\
\hline I use pro-environmental brands & 0.469 & 0.236 & 3.951 & 1 & 0.047 & 1.598 \\
\hline I take a short shower & 0.486 & 0.237 & 4.208 & 1 & 0.04 & 1.625 \\
\hline I prefer not to waste food & 0.171 & 0.734 & 0.054 & 1 & 0.816 & 1.187 \\
\hline I keep my car engine on while waiting & 0.172 & 0.238 & 0.522 & 1 & 0.47 & 1.188 \\
\hline I love nature & 0.17 & 0.887 & 0.037 & 1 & 0.848 & 1.186 \\
\hline Constant & -1.708 & 1.26 & 1.837 & 1 & 0.175 & 0.181 \\
\hline Chi-square value: $23.026 ;$ P-value: 0.003 & & & & & \\
\hline Overall percentage predicted: $64.7 \%$
\end{tabular}


The odds of printing papers on both sides are 1.742 times greater for those who attended any activity or seminar on the environment in the last year. Similarly, the odds of using proenvironmental brands is 1.598 times greater for those who attended any activity or seminar on the environment in last year. Lastly, the odds of taking a short shower is 1.625 times greater for those who attended any activity or seminar on the environment in the last year (Table 3). The results imply that environmental conservation habits can be inculcated by increasing awareness through extracurricular activities like seminars, talks and likewise.

\section{Discussion}

The research study is based on environmental sustainability awareness in Saudi Arabia. To understand the perspective of the respondents, in particular to the university students, the survey was conducted, the data collected, then, analyzed to produce outcomes. A total of 365 participants were surveyed. A questionnaire was used that included a comprehensive range of items consisting of demographic information, questions on the responsiveness of environmental concerns, questions on facts of environmental issues, and questions on behavior toward environmental problems. The results of the study show that the majority of the participants agree that they are nature lovers, $86 \%$ are Saudi nationals, among them $52 \%$ are female and $79 \%$ are from Prince Sattam Bin Abdulaziz University, and 76\% of them were from Business Administration college/major.

The hypothesis testing reveals that the Saudi nationals are better than non-Saudi nationals in terms of conserving the environment by saving paper while printings. In terms of gender and air pollution, males are better than females. While, in terms of difference across Universities, there is a substantial variance between students of Prince Sattam Bin Abdulaziz University and other universities as PSAU tend to use environmental brands more than other university students. For the study major, students in business majors tend to use pro-environmental brands more than other university students.

\section{Conclusion}

Though all the respondents believe that conserving the environment is important, out of the seven identified environmental conservation habits, respondents reported not being aware and/or not following four habits awareness. These are using pro-environmental brands, taking a short shower, keep a car engine running while waiting, and printing papers on both sides. This may be attributed to a lack of awareness about these activities.

The majority of respondents closed the water taps while brushing (88\%), switch off the lights when going out $(91 \%)$, and prefer not to waste food $(98 \%)$. The study identifies a few environmental awareness habits and looks for differences across characteristics of the respondents. In terms of nationality, gender, university, and major, there is a difference only in terms of one particular habit. Similarly, in terms of gender, there is a difference in terms of two habits.

And most importantly, there is a significant difference in three different habits concerning environment-related activities on their campus in the past year. Finally, the results of logistic regression indicate that the probability of printing papers both sides, using pro-environmental brands, and taking a short shower is greater for those who attended any activity or seminar on the environment in the last year. The results imply that environmental awareness can be increased using activities on sustainability issues. The study recommends an increasing number of extracurricular activities on environmental topics as only $38 \%$ of the respondents reported any activity on the environment in the past year.

\section{References}

Abolore, A. A. (2012). Comparative Study of Environmental Sustainability in Building Construction in Nigeria and Malaysia. Journal of Emerging Trends in Economics and Management Sciences, 3(6), 951-961.

Albahlal, A. Alqahtani S, \& Al-Muqri, A. H. (2017). Sustainability Awareness in Saudi Arabia. In: T. Issa et al. (eds.), Sustainability, Green IT and Education Strategies in the Twenty-first Century, Green Energy, and Technology. Cham, Switzerland: Springer International Publishing AG. DOI: 10.1007/978-3-319-57070$9 \_13$

Awan, U., \& Abbassi, A. S. (2013) Environmental Sustainability through Determinism the Level of Environmental Awareness, Knowledge and Behaviour among Business Graduates. Research Journal of Environmental and Earth Sciences, 5(9), 505-515.

Bradley, T. M., Waliczek, T. M., \& Zajick, J. M. (1999). Relationship between environmental knowledge and environmental attitude of high school students. Journal of Environmental Education, 30(3), 17-2.

Brundtland Commission Report. (1987). Report of the World Commission on Environment and Development: Our Common Future. United Nations. Retrieved April 20, 2020 from: https://www.are.admin.ch/are/en/home/sustainabledevelopment/international-cooperation/2030agenda/un-_milestones-in-sustainable-development/1987--brundtlandreport.html

Chuanhuia, Z., \& Hanweib, Z (2011). Cultivation of environmental values for university students under the strategic background of environmental informationization. Energy Procedia, 5, 945-951.

Corcoran, P. B., \& Wals, A. J (2004). Higher Education and the Challenge of Sustainability, Problematics, Promise and Practice. Dordrecht, Netherlands: Kluwer. 
Dagher, G. K., Itani, O., \& Kassar, A. N. (2015). The impact of environment concern and attitude on green purchasing behavior: gender as the moderator. Contemporary Management Research, 11(2), 179-206. DOI:10.7903/cmr.13625

Derckx, J. M. A. (2015). Pro-environmental behavior: Identifying determinants that could predict different types of proenvironmental behavior. S1378066. Available at: https:// essay.utwente.nl/67976/1/Derckx\%20Janneke\%20-s\%20 $1378066 \% 20$ scriptie.pdf

Duerden, D. M., \& Wit, A. P (2010). The impact of direct and indirect experiences on the development of environmental knowledge, attitudes, and behavior. Journal of Environmental Psychology, 30, 379-392. doi:http://dx.doi.org/10.1016/j. jenvp.2010.03.007

Gonzalez, A. L., \& Amerigo, M. (2008). Relationship among values, beliefs, norms and ecological behavior. Psicothema, 20(4), 623-629.

Gray, P. C. R., \& Wiedemann, P. M. (1999) Risk Management and sustainable development: Mulinal lessons from approaches to the use of indicators. Journal of Risk Research, 2(3), 201-218.

Hashmi, M. A., \& Al-Habib, M. (2013) Sustainability and carbon management practices in the Kingdom of Saudi Arabia. Journal of Environmental Planning and Management, 56, 140-157. DO I:10.1080/09640568.2012.654849

Holt, D. (2003). The role and impact of the business school curriculum in shaping environmental education at Middlesex University. International Journal of Sustain Higher Education, 4(4), 324-342.

Jianguo, M. (2004) Teaching Environmental Awareness in Mathematics. Chinese Education and Society, 37(4), 53-56. https://doi.org/10.1080/10611932.2004.11031651

Karban, A. (2014) Developing a framework for neighborhood-level urban sustainability assessment in Saudi Arabia. Doctoral Thesis. The University of Texas at San Antonio, San Antonio

Kellstedt, P. M., Sammy, Z., \& Arnold, V (2008). Personal efficacy, the information environment and attitudes toward global warming and climate change in the United States. Risk Analysis, 28(1), 113-126.

Kilbourne, W. E., \& Polonsky, J. M. (2005). Environmental attitudes and their relation to the dominant social paradigm among university students in New Zealand and Australia. Environmental Attitudes, 13(2), 37-48.

Lee, C., \& Lim, S. Y. (2020) Impact of environmental concern on Image of Internal GSCM practices and consumer purchasing behavior. Journal of Asian Finance, Economics and Business, 7(6), 241-254. DOI:10.13106/jafeb.2020.vol7.no6. 241

Leeuw, A. D., Valois, P., Ajzen, L., \& Schmidt, P. (2015). Using the theory of planned behavior to identify key beliefs underlying pro-environmental behavior in high school students: implications for educational interventions. Journal of Environmental Psychology, 42, 128-138. http://dx.doi. org/10.1016/j.jenvp.2015.03.005

Madsen, P. (1996). What can Universities and Professional Schools do to Save the Environment? In: J. B. Callicott \& F. J. da Rocha (Eds.), Earth Summit Ethics: Toward a Reconstructive Postmodern Philosophy of Environmental Education (pp. 71-91). Albany, NY: Albany State University of New York Press.

Moody, G., Alkaff, H., Garrison, D., \& Golley, F (2005). Assessing the environmental literacy requirement at the University of Georgia. Journal of Environmental Education, 36(4), 3-9.

Nguyen, T. K. T. (2020). Studying factors affecting environmental accounting implementation in mining enterprises in Vietnam. Journal of Asian Finance, Economics and Business, 7(5), 131-144. doi:10.13106/jafeb.2020.vol7.no5.131

Ogunbonde, C. A., \& Arnold, K. (2012). A study on environmental awareness and attitudes in Ibadan, Nigeria. Human Ecological Risk Assessment, 18, 669-684. http://dx.doi.org/10.1080/10807 039.2012.672901

Saifullah, M. K., Kari, F. B., \& Ali, M. A (2017). Linkage between public policy, green technology and green products on environmental awareness in the urban Kaula Lumpur, Malaysia. Journal of Asian Finance, Economics and Business, 4(2), 45-53. Doi:10.13106/jafeb.2017.vol4.no2.45

Schusler, T. M., \& Krasny, M. E. (2010). Environmental action as a context for youth development. Journal of Environmental Education, 41(4), 208-223.

Wolfe, V. (2001). A survey of the environmental education of students in non-environmental majors at four-year institutions in the USA. International Journal Sustainable Higher Education, 2(4), 301-15.

Ziadat, H. A. (2010). Major factors contributing to environmental awareness among people in a third world country/Jordan. Environment, Development and Sustainability, 12, 135-145. DOI 10.1007/s10668-009-9185-4

Zsoka, A., Szerényi, Z. M., Szechy, A., \& Kocsis, T. (2012). Greening due to environmental education? Environmental knowledge, attitudes, consumer behavior, and everyday pro-environmental activities of Hungarian high school and university students. Journal of Cleaner Production, 48, 126-138. https://doi.org/10.1016/j.jclepro.2012.11.030 